\title{
Stable isotope ratio analysis as a new tool to trace the geographical origin of Argan oils in Morocco
}

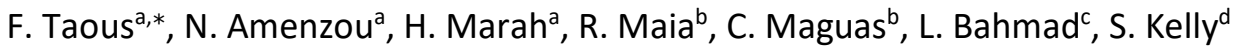 \\ a Centre National de l'Energie des Sciences et des Techniques Nucleaires (CNESTEN) Rabat, Morocco \\ b cE3c, Centre for Ecology, Evolution and Environmental Changes, Plant Biology Department, Faculdade de Ciencias, \\ Universidade de Lisboa, FCUL, Campo Grande, Bloco C2, Piso 5, 1749-016 Lisboa, Portugal \\ c Laboratory of Condensed Matter and Interdisciplinary Sciences (LaMCScl), Faculty of Sciences, Mohammed V University in \\ Rabat, Morocco \\ d Food and Environmental Protection Laboratory, Joint FAO/IAEA Division of Nuclear Applications in Food and Agriculture, \\ Department of Nuclear Sciences and Applications, International Atomic Energy Agency, Vienna International Centre, PO Box \\ 100, 1400 Vienna, Austria
}

\begin{abstract}
A B S T R A C T
Argan oil is obtained from the fruits of the Argan tree (Argania spinosa), an endemic species from south-western Morocco. Oil is extracted from Argan seeds through a traditional or a semi-automated process. In the case of edible oils, seeds are roasted before extraction, but when the oil is used for cosmetics, no seed roasting is required. Several cooperatives and private enterprises are established in south-west Morocco producing and commercializing edible and Cosmetic Argan oil. The identification of the geographical origin of Argan oils is attracting great interest from consumers and producers since it may be used as a criterion for guaranteeing quality and authenticity. Stable isotope techniques can provide useful information on the origin of food products. For these reasons the natural abundance isotopic ratios of Carbon, Oxygen and Nitrogen were measured using isotope ratio mass spectrometry (IRMS) for samples (cosmetics oil, seed) produced between July and August 2012 in different Moroccan cooperatives with certified PGI (protected geographical indication) label and organic certification, representing five provenances in the southwest part of Morocco. These provenances are distinct on a Geographical, hydrological and climatic level: Essaouira, Agadir Idaou Tanane, chtouka Ait Baha, Taroudant and Tiznit.

IRMS was selected as a reliable technique to characterise the stable carbon and oxygen isotope 'fingerprints' of Moroccan Protected Geographical Indication (PGI) Argan oils and nitrogen isotope analysis of the Agan nut. Moreover, it demonstrated relationships between environmental parameters and the isotopic composition of plants coming from geographically distinct areas. The results obtained in this study indicate that it is possible to differentiate Argan oil producing areas, which can be associated with regional (cooperatives), and promote and protect the quality and commercial value of this important Moroccan plant product.
\end{abstract}

\section{Keywords:}

Argan oil; Carbon oxygen; Nitrogen stable isotopes; Protected geographical indication; Stable isotope fingerprint 


\section{Introduction}

The impacts and variations that result in changes to modern environments may be expressed in changes in the hydrogen $(\mathrm{H})$, carbon $(\mathrm{C})$, nitrogen $(\mathrm{N})$ and oxygen $(\mathrm{O})$ isotope ratios of atmospheric gases, animal and plant tissues, soil organic matter and its diverse chemical substrates, the carbonates of teeth, corals and soils, the organic matter deposited in sediments, as well as water sources in the hydrosphere and the atmosphere [1]. Any type of sample that is analysed for its isotope composition, particularly over a given period of time, can be regarded as an archive of environmental, agricultural or technological change. The isotope ratios of plant and animal tissues used in the food supply chain represent a temporal integration of significant physiological and ecological processes occurring on the landscape during their production. The timescale of this integration depends largely on the element turnover rate of the tissue or pool in question [2]. Additionally, isotopes provide information about the occurrence and magnitude of key ecological processes [3-5]. The presence or absence of such processes and their magnitude in relation to other processes are often indicated by the stable isotope ratio value relative to known background levels. Many ecological processes produce a distinctive isotope ratio fingerprint, and, for that reason, it becomes possible to discriminate the geographical origin of the plant or animal tissues [4-9]. The use of this physical parameter may allow for the discrimination between samples that may be identical from their chemical-composition point of view. Also, isotopes record biological responses to Earth's changing environmental conditions. For cases in which substances or residues accumulate in an incremental manner, such as tree rings, animal hair and ice cores, isotope ratios can be regarded as a temporal record of system response to changing environmental conditions or as a proxy record for environmental change.

Isotope-based research has developed steadily over the last 60 years and has become an important part of many studies in the fields of ecology, geochemistry, biochemistry and archaeology and more latterly food authenticity and forensics.

Isotope analysis of chemical elements of plant seeds or of specific organic compounds extracted from those seeds may permit the understanding of different ecological processes and their influence on plant development and physiology during the seed developmental period. Because this is intrinsically related with local climatic conditions (i.e., temperature, precipitation, air humidity), results generally facilitate the development of analytical tools supporting verification of the provenance of the plant material and any associated traceability systems $[10,11]$.

In this research, an economically important Moroccan plant species was selected as a case-study, namely the Argan tree (Argania spinosa), a species endemic to south western Morocco and protected by UNESCO (2007). The tree, a relict species from the Tertiary age, is extremely well adapted to drought and other environmentally difficult conditions of southwestern Morocco. Nevertheless, under such difficult conditions, the plants are highly productive, living up to 200 years, with Argan forests occupying approximately 830,000 ha, in the triangle formed by Essaouira, Agadir and Taroudant regions. The total production of Argan oil varies from 3000 to 4000 tons per annum and represents a maximum 1.6\% of food oil consumed in Morocco [12]. Argan oil production plays a key role in the environmental and socio-economic context of Morocco. Within the Moroccan society, the Argan oil production chain supports the livelihoods of approximately 2.2 million people, among them economically-vulnerable groups, such as women, who have organized themselves into cooperatives not only in the major Argan oil-producing regions, but also throughout the country (De Waroux, 2013). Additionally, A. spinosa provides animal forage, shelter and soil protection against desertification $[13,14]$. Indeed, the integrated value of this product relies on Mediterranean biodiversity, traditional knowledge and heritage and on social organization and promotion of territorial products.

Although Argan oil is exploited commercially, especially in the cosmetic sector, little published information is available on the authentication and verification of origin of this product as well as on the artisanal production methods and technologies that can claim a truly Moroccan identity and origin. High quality and Geographically Indicated (GI) brands have success on the foodstuff markets, including exportation, since consumers are willing to pay more for identifiable products with a declaration of origin [15]. The reasons include ethnocentrism, specific organoleptic or 
culinary qualities of regional products, or concern over the quality and safety of non-local products. Specific products protected by geographical indications may differentiate small local industries, increasing their visibility by simultaneously protecting, promoting and helping to sustain small and local producers alongside larger businesses that usually steer the market $[16,17]$. On the other hand, the rapid development of markets for cosmetic Argan oil (starting during mid-2000 s), which is expected to continue to grow [18], caused loss of control over its traceability and quality. In order to protect and promote this product, in 2010 Argan oil received the PGI designation by the Moroccan Government, which legally protects it from other oils and/or production methods.

Morocco is known to be the only country that produces Argan oil. Thus, due to the economic, social and cultural importance of Argan oil in Morocco, there is a clear requirement to verify its authenticity and provenance in order to protect and promote this unique and high-value Moroccan agricultural product.

The aim of this study was to characterise the geographical origin of the most important Argan oil production regions of Morocco using stable isotope ratios of heavy and light elements. This may lay the foundations for a verifiable geographical origin certification that helps to define the local biodiversity and socio-cultural heritage in this region of the Mediterranean, which ultimately substantiates the value of such a unique product. In our study, we have combined, for the first time, isotope ratio analysis of carbon, nitrogen and oxygen (analysed by IRMS) with environmental parameters in order to characterise and distinguish the five most important areas of Moroccan Argan oil production.

\section{Materials and methods}

\subsection{Samples and climate}

The Argan tree stands that have been the subject of this study cover the largest portion of the Macaron Siene ecoregion, from Safi to the fringes of the Sahara and bounded by the Atlantic Ocean to the west and the Atlas Mountains to the east. Its geographic distribution is limited, located $29^{\circ} 15^{\prime}$ to $31^{\circ} 20^{\prime} \mathrm{N} ; 8^{\circ} 10^{\prime}$ to $10^{\circ} 25^{\prime} \mathrm{W}$ (Fig. $1 \mathrm{~A}$ ). This area covers hot and temperate arid bioclimates to warm and temperate semi-arid and Saharan in the south. The rainfall is typically between 250 and $400 \mathrm{~mm}$ from Essaouira to Agadir. In the Souss plain and the Anti-Atlas, annual precipitation ranges from 150 to $250 \mathrm{~mm}$. Further south, in the Saharan zones, there is often less than $100 \mathrm{~mm}$ of rainfall and the Argan trees are located only along the temporary seasonal streams.

All samples were collected in the Provinces of Essaouira, Agadir Idaou Tanan, Taroudant, Chtouka Ait Baha, and Tiznit (Fig. 1A). All samples are from unroasted kernels and are produced by the Womens' Cooperatives Markets, using mechanical extraction (Table 1).

A total of 24 cosmetic Argan oil samples harvested between July and August 2012 were collected from co-operative production, known and certified PGI (Protected Geographical Indication) in the field of oil extraction by NORMACERT (control and certification organism approved by the Ministry of Agriculture). These co-operatives (Fig. 1B), referenced to the AMIGHA [27] (Moroccan Association of the Geographical Indication of Argan Oil), are distributed on the three climate areas (arid, semi-arid and Saharan) that represent all the areas of Argan tree distribution in Morocco. The extraction process includes mechanical cleaning the nut from pulp, manual cracking and seed separation from the stone, mechanically pressing them, and finally filtering the oil obtained through a cellulose-plate filter (Table 2).

Argan oil samples were placed in dark amber glass bottles, wrapped in aluminum foil and stored in the dark at room temperature until analysis. The samples were 2 to 3 months old (from production date) at the time of analysis.

Latitude and longitude data were obtained with Google Earth software, version 5.0, 15, and calculated annual mean oxygen stable isotope values of precipitation $\left(\delta^{18} \mathrm{Oprec}\right)$ were imported from the online tool available at http://www.waterisotopes.org [19]. Information on temperature (daily mean values for each geographical location) were acquired from the https://fr.climate-data.org/.

\subsection{Stable isotopes measurements}




\subsubsection{Isotope ratio mass spectrometry (IRMS)}

Stable isotope ratios were determined with a Finnigan MAT (Bremen, Germany) Delta V Mass spectrometer, interfaced on-line with a Carlo Erba (ThermoQuest, Milan, Italy) CHN 2500 elemental analyzer (EA) for ${ }^{13} \mathrm{C} /{ }^{12} \mathrm{C}$ sample combustion, and isotope ratio mass spectrometers (ThermoFisher, Delta $\mathrm{V}$, Bremen, Germany) connected to a high temperature EA (TC/EA, Thermo Finnigan) for ${ }^{18} \mathrm{O} /{ }^{16} \mathrm{O}$.

The analytical procedures adopted for measuring the ${ }^{13} \mathrm{C} /{ }^{12} \mathrm{C}$ ratios are described in Angerosa et al., [20], whereas the analytical procedures adopted for measuring the ${ }^{18} \mathrm{O} /{ }^{16} \mathrm{O}$ ratios are described in Breas et al., [21] and Camin et al., [22]. The measurements are expressed as parts per thousand ( $\delta \%$ ) versus V-PDB (Vienna - Pee Dee Belemnite) for $\delta^{13} \mathrm{C}$, and V-SMOW (Vienna - Standard Mean Ocean Water) for $\delta 180$ according to the following formula:

[(Rs-Rstd)/Rstd]*1000, where Rs is the isotope ratio measured for the sample and Rstd is the isotope ratio of the international standard. The values were calibrated against in-house oil standards, which were themselves calibrated against international reference materials: fuel oil NBS-22 (IAEA, http://curem.iaea.org/catalogue/SI/index.html) and sugar IAEA-CH-6 (IAEA), for ${ }^{13} \mathrm{C} /{ }^{12} \mathrm{C}$, International Atomic Energy Agency benzoic acid reference materials IAEA-601 and IAEA-602.

\subsubsection{Combustion (EA-C) mode}

Argan oils $(0.3 \mathrm{mg})$ were weighed into tin capsules, sealed and dropped into an elemental analyzer reaction tube containing chromium oxide at $1020^{\circ} \mathrm{C}$. Simultaneously the helium carrier gas is temporarily replaced with oxygen gas to quantitatively convert the oil sample into carbon dioxide, nitrogen oxides and water. The combustion products then pass into a second reactor containing copper wires at $650^{\circ} \mathrm{C}$ that quantitatively converts the nitrogen oxides to nitrogen gas and prevent excess oxygen reaching the ion source. Water vapour was removed by a chemical trap $(10 \mathrm{~mm}$ i.d., length $0.2 \mathrm{~m}$ ) containing magnesium perchlorate. The carbon dioxide and nitrogen gasses were then separated on a packed GC column (Porapak, $4 \mathrm{~mm}$ i.d. $\times 2 \mathrm{~m}$ length). The GC effluent was introduced into a stable isotope ratio mass spectrometer (Delta XP, Thermo Finnigan, Bremen, Germany) via an interface and the ratio of the isotopologues of carbon dioxide and nitrogen determined against reference gasses of known ${ }^{13} \mathrm{C} /{ }^{12} \mathrm{C}$ and ${ }^{15} \mathrm{~N} /{ }^{14} \mathrm{~N}$ ratios versus accepted international standards, respectively. Precision (standard deviation of the set of standards analyzed in each batch, $\mathrm{n}=6$ ) was $0.06 \%$ for carbon, $0.08 \%$ o for nitrogen. The overall standard deviations obtained for $\delta^{13} \mathrm{C}$, and $\delta^{15} \mathrm{~N}$, were 1.4 , and 0.8 , respectively.

\subsubsection{Pyrolysis (EA-P) mode}

Aliquots of sample $(0.6 \mu \mathrm{g})$ were weighed into silver capsules for measurement of ${ }^{18} \mathrm{O} /{ }^{16} \mathrm{O}$ on isotope ratio mass spectrometer coupled to a high-temperature elemental analyzer maintained at $1450{ }^{\circ} \mathrm{C}$. The silver capsules were dropped into a glassy carbon reactor containing glassy carbon chips and nickel-plated carbon as catalysts, mounted coaxially in a ceramic tube [16]. The pyrolysis gases were swept by a flow of helium carrier gas (grade 5.6, flow rate 100 $\mathrm{cm} 3 / \mathrm{min}$ ). The resulting pyrolysis products, carbon monoxide and hydrogen, were swept by helium carrier gas to two chemical traps, one containing magnesium perchlorate, the other containing carbosorb, to remove unwanted water vapor and $\mathrm{CO}_{2}$ respectively. The analysis gasses then passes through a packed Molsieve $5 \mathrm{~A} \mathrm{GC}$ column (4mm i.d., length $2 \mathrm{~m}$ ) heated to $80^{\circ} \mathrm{C}$. A portion of the effluent (approximately $0.1 \mathrm{~mL} / \mathrm{min}$ ) flows via the open split into the ion source of the IRMS, allowing the measurement of the oxygen $\left(\delta^{18} \mathrm{O}\right)$ isotope ratio of the sample by comparison with the known isotope ratio of relevant carbo monoxide reference gas versus V-SMOW. Analytical performance, stability and drift, was checked by inserting laboratory standards between samples. Correction was made when necessary. Replicate precision was typically $0.15 \%$. Oxygen isotopic composition of 24 individual Argan oils yielded a standard deviation for $\delta^{18} \mathrm{O}$ of $0.5 \%$.

\subsubsection{Modeling geospatial signatures (GIS)}


The authentication and verification of the geographical origin of food commodities are important topics in the food sector. This study shows the spatial variability "GIS modeling Isoscapes" of carbon and oxygen stable isotope compositions $\left(\delta^{13} \mathrm{C}, \delta^{18} \mathrm{O}\right)$ of Argan oil samples collected in 2012. In order to make global, spatially continuous predictions for Argan oils stable isotope ratios, we implemented these mechanistic models in ArcGIS software (ESRI Corporation ArcGIS 10.5). We used ordinary point kriging to spatially interpolate $\delta^{13} \mathrm{C}$ and $\delta^{18} \mathrm{O}$ values of Argan oils from 25 individual samples collected at 5 independent regions that were selected for model development. This geospatial approach can be used to define a protocol for analyzing the isotopic composition of cosmetic Argan oil in order to certify their origin and prevent food fraud.

\section{Results and discussion}

\subsection{Impact of the local geographical parameters Latitude, Altitude, and distance from the sea effect}

The $\mathrm{C}$ and $\mathrm{O}$ isotopic composition of Argan oil, and of plant materials in general, is related to the climatic conditions (relative humidity, temperature, amount of precipitation) and geographical characteristics (distance from the sea or other evaporation source, altitude, latitude) of the area where the plants grow [23] and to the plant variety [24]. The ${ }^{13} \mathrm{C} /{ }^{12} \mathrm{C}$ ratios of plant compounds are significantly affected by the plant species and the photosynthetic pathway used for assimilation of $\mathrm{CO}_{2}$ (discrimination between $\mathrm{C} 3$ and $\mathrm{C} 4$ plants) and, to a lesser extent, by several environmental and physiological factors that influence the stomatal conductance and the intercellular and ambient $\mathrm{CO}_{2}$ concentration, such as relative humidity, temperature, amount of precipitation, water stress, plant age and maturation [25]. The ${ }^{18} \mathrm{O} /{ }^{16} \mathrm{O}$ (and ${ }^{2} \mathrm{H} /{ }^{1} \mathrm{H}$ ) ratios of plant materials reflect the ratios of the water taken up by the plant (linked to latitude, elevation, distance from the evaporation source, temperature and amount of precipitation), the evaporative and diffusional effects during transportation (affected by relative humidity, temperature, isotope composition of water vapor) and the biosynthetic pathways including the isotopic exchange between organic molecules and plant water in plant organs [25].

The values measured for Argan oil and nut samples collected mainly during April 2012 in this study are shown in Table 1 of the Supporting Information. The results of the isotopic analyses $\left(\delta^{13} C, \delta^{18} O\right.$ and $\left.\delta^{15} N\right)$ of the samples of Argan oil and nut present broad variation of the isotopic abundance with geographical characteristics, altitude, latitude, and distance from the sea (Figs. $2 \mathrm{~A}-\mathrm{C}$ ), which demonstrate the importance of carbon, oxygen and nitrogen stable isotopes for the traceability study. The carbon isotopic values $\left(\delta^{13} \mathrm{C}\right)$ of Argan nut varied from $-25.7 \%$ o to $-30.1 \%$ o $( \pm 0.2 \%$ ). These values were enriched in relation to the correspondent Argan oils that ranged from $-26.3 \%$ o to $-29.9 \%$ ( $\pm 0.2 \%$ o). The oxygen isotope values $\left(\delta^{18} \mathrm{O}\right)$ ranged from $26.3 \%$ o to $31.3 \%$ o $( \pm 0.2 \%$ ) and these values were also enriched in relation to the correspondent Argan oils that ranged from $23.3 \%$ to $29.9 \%$ o $\left( \pm 0.2 \%\right.$ ). The $\delta^{13} \mathrm{C}$ and $\delta^{18} \mathrm{O}$ values of Argan oil increase with increasing altitude (Figs. 2A, B) and showed a negative trend with latitude and these values also suggest the occurrence of a "continental isotope effect" with the coastal oils showing more enriched isotope values. The Nitrogen isotopic composition in Argan oil seed indicated that traditional agro pastoral activities that are common in Argania forests may influence $\delta^{15} \mathrm{~N}$ values of these plant materials. Argan nut and paste $\delta^{15} \mathrm{~N}$ values ranged from $+3.1 \%$ up to enriched values as high as $+7.7 \%$ o possibly indicating animal manure fertilization. For each Argan oil, known values of latitude, longitude, and altitude allowed predicted values of $\delta^{18} \mathrm{O}$ of local precipitation to be obtained with the OIPC (The Online Isotopes in Precipitation Calculator) [26]. A positive correlation was obtained between the measured $\delta^{18} \mathrm{O}$ of the Argan oil and of the OIPC interpolated local precipitation in Agadir, Ait Baha and Taroudante $\delta^{13} \mathrm{C}, \delta^{18} \mathrm{O}$ values increased with altitude (Fig. 2B). The relationship between the $\delta^{13} \mathrm{C}, \delta^{18} \mathrm{O}$ stables isotopes of Argan oil and latitude showed a negative trend and suggested the occurrence of a "latitude isotope effect", with the coastal oils showing more enriched $\delta^{13} \mathrm{C}$ and $\delta^{18} \mathrm{O}$ values. This confirms the importance of carbon and oxygen stable isotopes for the geographical characterization of Argan oils.

\subsection{Distribution of $\delta 13 \mathrm{C}$ and $\delta 180(\%)$ values in the Argan tree according to principal geographical area}

The oxygen isotopic composition of the Argan oil samples varied by $6.6 \%$, from $23.3 \%$ (Essaouira) to $29.9 \%$ o (Taroudant and Tiznit). Furthermore, higher values of mean $\delta^{18} \mathrm{O}$ values were obtained for Argan oil produced at higher 
altitude. All Argan oils with $\delta^{18} \mathrm{O}$ greater than $27 \%$ were produced at altitudes of greater than $400 \mathrm{~m}$ (Fig. 2B). Argan oil from Drarga, Ait Abou, Tighanimin and Imsouan (Agadir), from Lazan, Aououz, and Iforir (Taroudante), and from lakhzas, Taourirt (Tiznit), produced at altitudes of greater than $400 \mathrm{~m}$, had a mean $\delta^{18} \mathrm{O}$ value from 27 to $30 \%$ (Fig. 2B). In comparison to these sites, Argan oil from the Essaouira region (Agred, Ounara, Bousmate, Tidzi, and Ait Aissi), and Ait Brahim, Aday and Tafraoute in Ait Baha, had lower mean $\delta^{18} \mathrm{O}$ values, ranging from 23.30 to $27 \%$ (Table 1). The High Atlas is a geographical barrier between the northern slope and the south side. The mean $\delta^{13} \mathrm{C}$ and $\delta^{18} \mathrm{O}$ values per region are shown in Fig. 3. The $\delta^{18} \mathrm{O}$ values allow for the distinction between Argan oil produced in the regions of Essaouira and Ait Baha the other production regions (Agadir Idaou Tanan, Taroudant and Tiznit).

The variabilities of $\delta^{13} \mathrm{C}$ and $\delta^{18} \mathrm{O}$ values over the principal geographical areas of Argan three productions are shown as an interpolated isotope landscape (isoscape) in Fig. 4, suggesting differences in water availability to the plants in these regions. Argan oils coming from the northern Morocco regions Essaouira, and Agadir Idaow Tanane, are characterized by a more temperate and humid climate (Fig. 2A) due to the proximity of the sea, resulting in significantly lower values for $\delta 13 \mathrm{C}$ (Fig. 4A). The $\delta 13 \mathrm{C}$ values can be explained by the similar latitude of these regions and the distance to the water sources. Some regions (i.e. taroudant, Chtouka ait Baha and Tiznit) show a large distribution of values due to the different conditions in which the plants can be cultivated in the Region Mountains, plains, close or far to the sea, etc...

Moreover, the $\delta 180$ values of samples coming from fruits grown in inland areas, characterized by higher temperatures and a dryer climate, for example, Taroudant, and Tafraout, exhibit a greater enrichment in $\delta 180$ than those produced in other regions located closer to the sea (Essaouira, Agadir, Ait Baha and Tiznit) (Fig. 4B). The observed dependence of $\delta 180$ values on geoclimatic parameters should not be surprising because it is known that enrichment in heavy isotopes of oxygen occurs in plant water due to evapotranspiration through leaf stomata prior to assimilation and incorporation into plant metabolite organic matter (Miahilova et al., 2015).

Plotting $\delta 13 \mathrm{C}$ values obtained for all of the examined oils versus their corresponding $\delta 180$ data (Fig. 5) shows that values from the five studied regions are clearly separated. Samples seem to arrange according to the climate of the region of the oil production and put in evidence a clear trend to cluster in relation to their geographical origin. The groups corresponding to the region Essaouira and Agadir Idaw Tanan are rather close. Agadir and Essaouira are two oceanic coastal regions with hot humid and arid bioclimate. The Taroudande region is surrounded by two mountain chains (High Atlas and Anti-Atlas) and has a hot semi-arid bioclimate, which is in fact the most different from the Agadir and Essaouira classes. Also, in the Taroudante region temperature average values reach $30{ }^{\circ} \mathrm{C}$ in summer and the average winter minimum is between 3 and $8^{\circ} \mathrm{C}$ (Table 1).

The regions Ait-Baha Tafraoute and Tiznite (Fig. 1) are geographically close. They have similar climate conditions. The winter is relatively warm and humid with a temperature of $25^{\circ} \mathrm{C}$ and the summer is hot arid with temperatures around $30{ }^{\circ} \mathrm{C}$. The difference between the annual precipitations (Figs. 2A, B) can also be a determining factor between two regions. The region Tafraoute Ait-Baha and Tiznite are characterized by an arid Mediterranean bioclimate, Saharan areas with desert nature and they are influenced by the variability of annual rainfall ranging from 100 to $250 \mathrm{~mm}$.

These results also indicate that the isotopic composition of oxygen of the Argan oil studied varies according to the altitude at which they are produced, a parameter that is known to influence the isotopic composition of local precipitation (due to changes in temperature).

\section{Conclusions}

This research has revealed the importance of isotope analysis to the differentiation of Argan forest products. Furthermore, it demonstrated relationships between environmental conditions and the plant organic materials' isotopic composition. Although additional work is clearly needed to clarify the mechanisms underlying many of these relationships and their temporal stability, the results obtained so far indicate that the isotopic composition of plant organic material from different regions may to some degree be predictable. Accordingly, this would support the use of 
stable isotopes as a tool for the verification of claims relating to Argan oil provenance. Furthermore, isotopes may contribute to trace the environmental impacts occurring in (semi)-arid regions, in particular if related with pasture activity, distance to the coast, anthropogenic activity and altitude. Additionally, other analytical variables such as multielement profiles, spectroscopic fingerprinting and chemical profiling could add to secure classification of geographical origin. Finally, it should be noted that the results are of great interest, to assure the traceability of Moroccan Argan oil and to contribute to the added value of the Protected Geographical Indication label of these products.

\section{Acknowledgements}

The authors are grateful to the Women Cooperative Markets from Ait-Baha, Agadir, Essaouira, Tiznit and Taroudant for providing the Argan oil samples. We thank Mohamed Ourais Hassan ALLALI, from AMIGHA (Marcaine Indication Geographies Association) for their support in cooperative and geological information.

\section{References}

[1] T.E. Dawson, R.T.W. Siegwolf, Using stable isotopes as indicators, tracers, and recorders of ecological change: some context and background, in: T.E. Dawson, R.T.W. Siegwolf (Eds.), Stable isotopes as indicators of ecological change, Elsevier, Burlington, 2007.

[2] T. Cerling, G.J. Bowen, J.R. Ehleringer, M. Sponheimer, The reaction progress variable and isotope turnover in biological systems, in: T.E. Dawson, T.W. Siegwolf (Eds.), Stable isotopes as indicators of ecological change, Elsevier, London, 2007.

[3] G.J. Bowen, J.B. West, J. Hoogewerff, Isoscapes: Isotope mapping and its applications, J. Geochem. Explor. 102 (2009) v-vii.

[4] T.E. Dawson, S. Mambelli, H. Plamboek, P.H. Templer, K.P. Tu, Stable isotopes in plant ecology, Annu. Rev. Ecol. Syst. 33 (2002) 507-559.

[5] J.B. West, H.W. Kreuzer, J.R. Ehleringer, Approaches to plant hydrogen and oxygen isoscapes generation, in: J.B. West, G.J. Bowen, T.E. Dawson, K.P. Tu (Eds.), Isoscapes, understanding movement, pattern, and process on Earth through isotope mapping, Springer, Dordrecht, 2010.

[6] M.M. Barbour, T.J. Andrews, G.D. Farquhar, Correlations between oxygen isotope ratios of wood constituents of Quercus and Pinus samples from around the world, Austr. J. Plant Physiol. 28 (2001) 335-348.

[7] G.J. Bowen, I.I. Wassenar, K.A. Hobson, Global application of stable hydrogen and oxygen isotopes to wildlife forensics, Oecologia 143 (2005) 337-348.

[8] G.J. Bowen, J.B. West, B.H. Vaughn, T.E. Dawson, J.R. Ehleringer, M.L. Fogel, K.A. Hobson, J. Hoogewerff, C. Kendall, C.T. Lai, C.C. Miller, D. Noone, H.P. Schwarcz, C.J. Still, Isoscapes to address large-scale Earth science challenges, EOS 90 (2009) 109-116.

[9] J.B. West, G.J. Bowen, T.E. Ceiling, J.R. Ehleringer, Stable isotopes as one of nature's ecological recorders, Trends Ecol. Evol. 21 (2006) 408-414.

[10] S. Kelly, K. Heaton, J. Hoogewerff, Tracing the geographical origin of food: the application of multi-element and multi-isotope analysis, Trends Food Sci. Technol. 16 (2005) 555-567.

[11] A. Gonzalvez, S. Armenta, M. De La Guardia, Trace-element composition and stableisotope ratio for discrimination of foods with Protected Designation of Origin, Trends Anal. Chem. 28 (2009) 1295-1311.

[12] M. Rahmani, Contribution à la connaissance de I'huile d'Argan Mémoire de 3ème Cycle, Institut Agronomique et vétérinaire, Rabat, 1979. 
[13] Z. Charrouf, D. Guillaume, L'huile d'Argan une production devenue adulte. Les technologies de laboratoire $\mathrm{N}^{\circ} 06$, septembre-octobre, 2007, pp. 4-7.

[14] Moussouris Yorgos, Pierce Alan, Biodiversity links to cultural identity in southwest Morocco: the situation, the problems and proposed solutions No. 48, November/ December, 2000.

[15] Annarita Antonelli, Hélène Ilbert, "Chapter 16. Legal protection of Mediterranean products ", in MediTERRA 2012 (english), Presses de Sciences Po (P.F.N.S.P.) «Annuels », 2012, pp. 327-344.

[16] R. Consonni, L. Cagliani, Nuclear magnetic resonance and chemometrics to assess geographical origin and quality of traditional food products, Adv. Food Nutr. Res. 59 (2010) 87-165.

[17] A. Gonzalvez, S. Armenta, M. De La Guardia, Trace-element composition and stable isotope ratio for discrimination of foods with Protected Designation of Origin, Trends Anal. Chem. 28 (2009) 1295-1311.

[18] M. Cherki, H. Berrougui, A. Drissi, A. Adlouni, A. Khalil, Pharmacol. Res. 54 (1) (2006) 1-5. Epub 2006 Mar 6. Argan oil: which benefits on cardiovascular diseases.

[19] G.J. Bowen, The Online Isotopes in Precipitation Calculator, version X.X. http://www.waterisotopes.org.

[20] F. Angerosa, L. Camera, S. Cumitini, G. Gleixner, F. Reniero, Carbon stable isotopes and olive oil adulteration with pomace oil, J. Agric. Food Chem. 45 (1997) 3044-3048.

[21] O. Breas, E. Sada, F. Reniero, C. Guillou, F. Angerosa, Oxygen-18 measurement by continuous flow-pyrolysisIsotope ratio mass spectrometry of vegetable oils, Rapid Commun. Mass Spectrom. 12 (1998) 188-192.

[22] F. Camin, Roberto Larcher, Matteo Perini, Luana Bontempo, Daniela Bertoldi, Giacomo Gagliano, Giorgio Nicolini, Giuseppe Versini, Characterisation of authentic Italian extra-virgin olive oils by stable isotope ratios of $\mathrm{C}, \mathrm{O}$ and $\mathrm{H}$ and mineral composition, Food Chem. 118 (2010) 901-909.

[23] A. Hermann, S. Voerkelius, Meteorological impact on oxygen isotope ratios of German wines, Am. J. Enol. Vitic. 59 (2008) 194-199.

[24] M.A. Aramendia, A. Marinas, J.M. Marinas, J.M. Moreno, M. Moalem, L. Rallo, F.J. Urbano, Oxygen-18 measurement of Andalusian olive oils by continuous flow pyrolysis/isotope ratio mass.

[25] Federica Camin, Luana Bontempo, Luca Ziller, Cristiana Piangiolino, Gianni Morchio/ Stable isotope ratios of carbon and hydrogen to distinguish olive oil from shark squalene-squalane.

[26] G.J. Bowen, The Online Isotopes in Precipitation Calculator, version 2.2, 2011. http://www.waterisotopes.org.

[27] AMIGHA: Association Marocaine de l'Indication Géographique de I'Huile d'Argane, 2010. Lettre d'information $\mathrm{N}^{\circ} 3-$ Avril. 


\section{List of Figures}

A

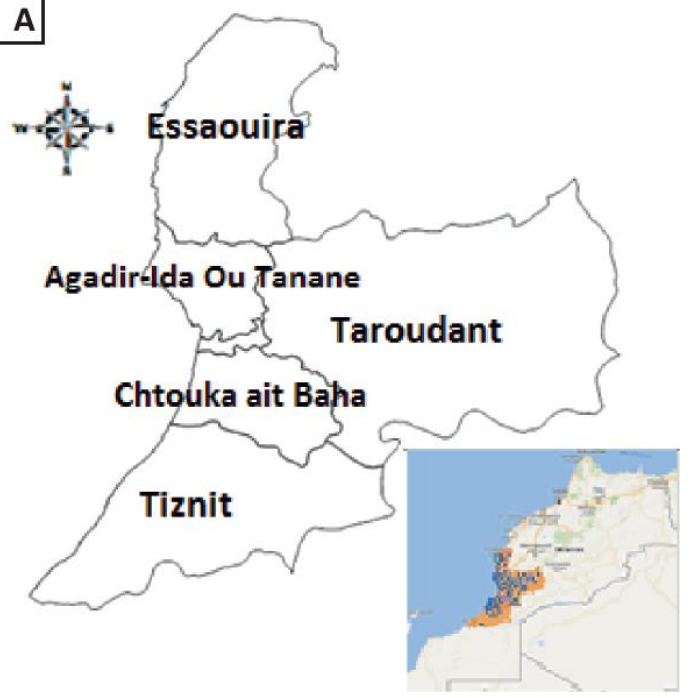

Fig. 1A. Moroccan regions where Argan seed samples obtained by cooperatives.

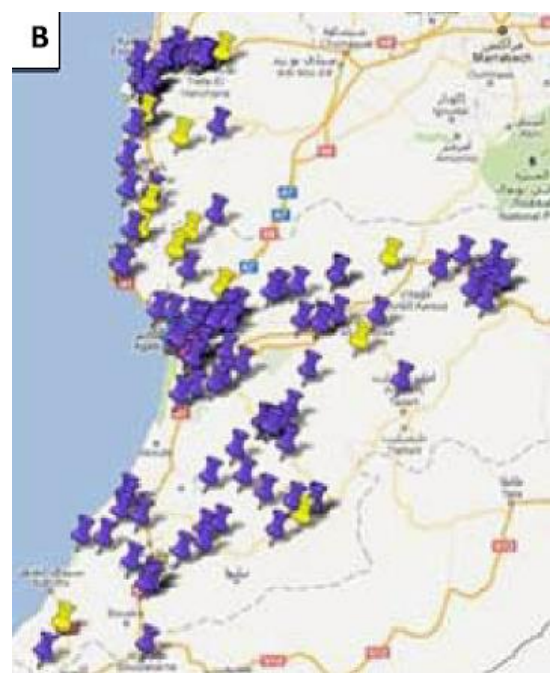

Fig. 1B. Geographical distribution of Certified Cooperatives (yellow) (ref: AMIGA/Satellite photos).
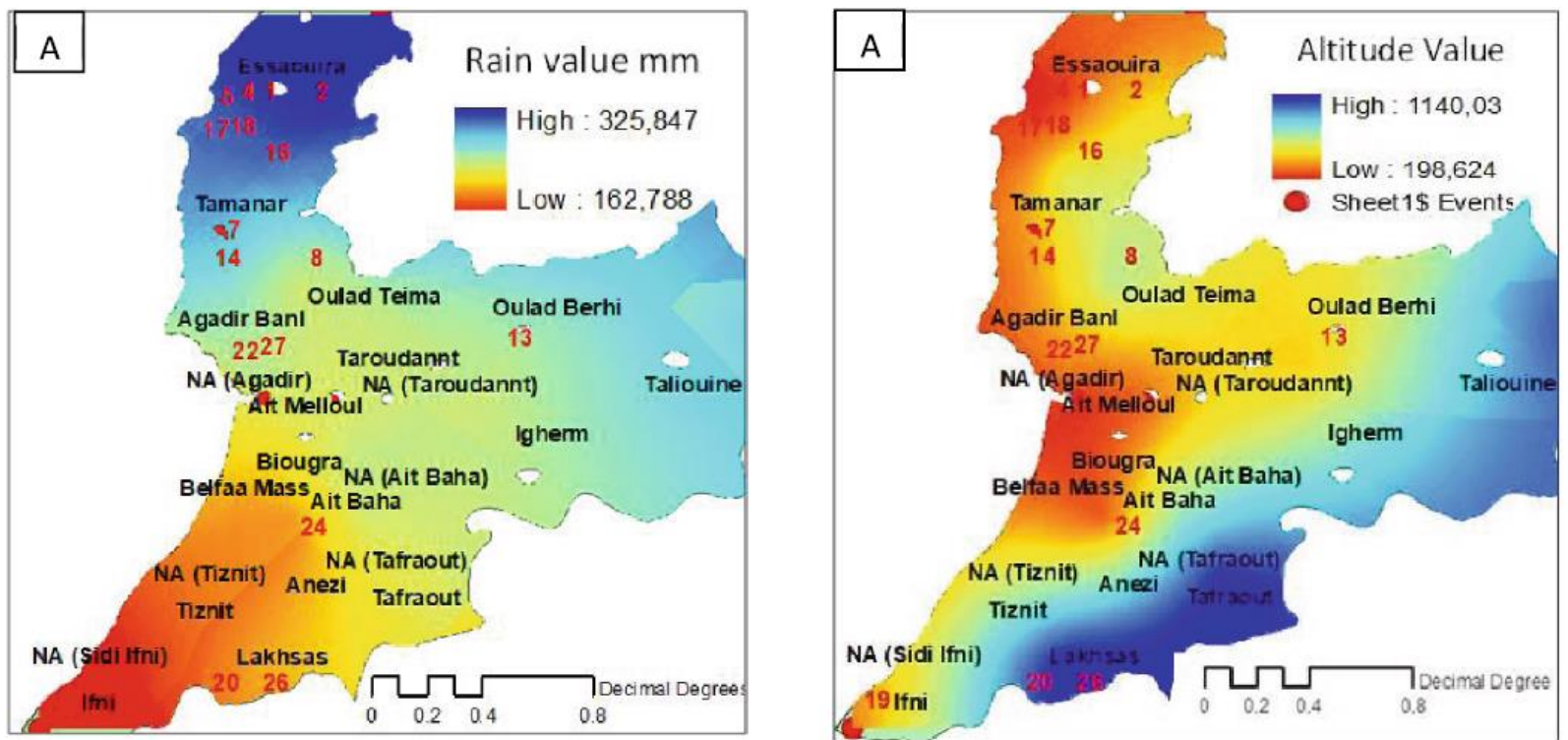

Fig. 2A. Isoscapes of rain and altitude of the Shoutern Moroccan basin. 

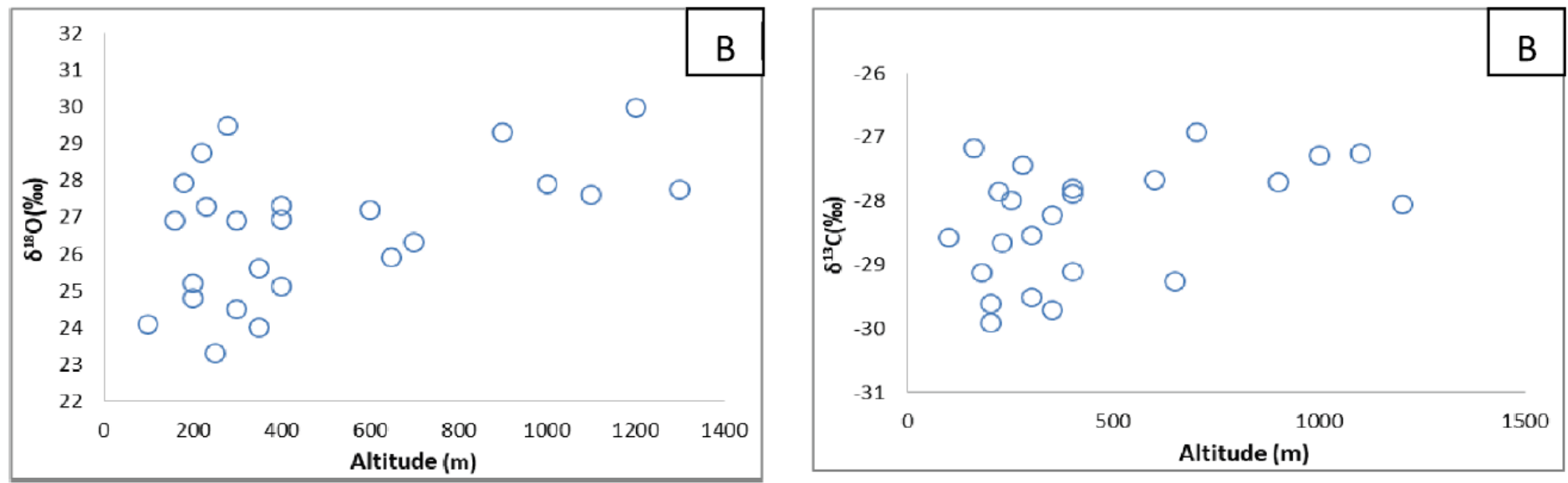

Fig. 2B. $\delta^{18} \mathrm{O}$ and $\delta^{13} \mathrm{C}$ Argan oil versus Altitude.

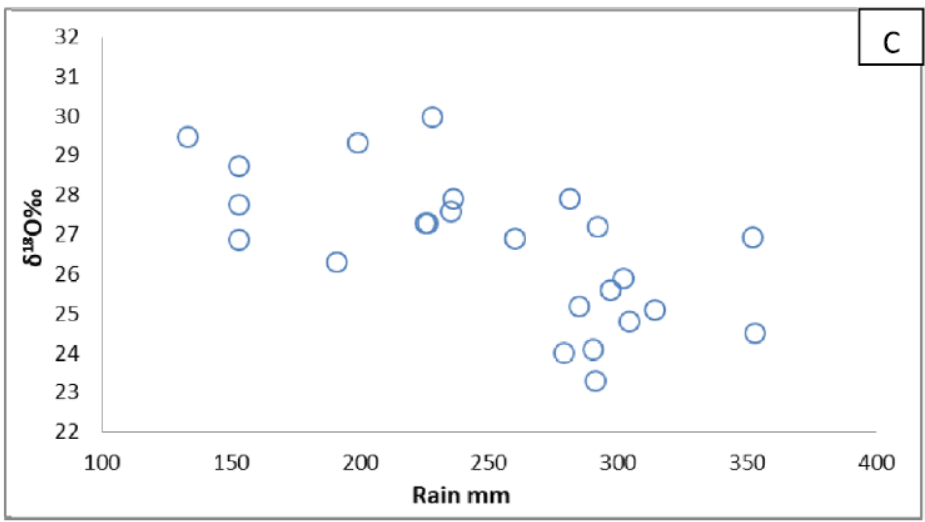

Fig.2C. $\delta^{18} \mathrm{O}$ Argan oil versus amount of precipitation.
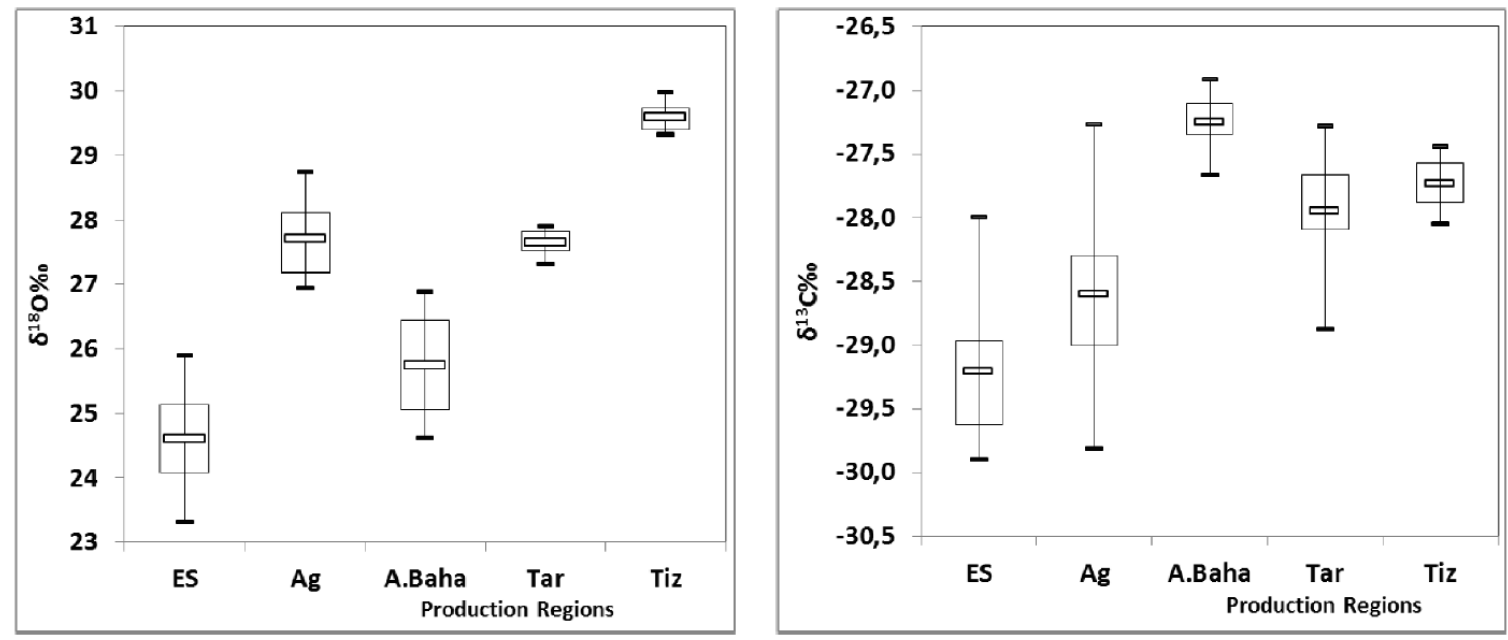

Fig. 3. Box-whisker $\delta^{18} \mathrm{O}$ and $\delta^{13} \mathrm{C}$ Argan oil samples collected in different region (Essaouira (Es), Agadir (Ag), Ait Baha Tafraout (A. Baha), Taroudant (Tar), and Tiznit (Tiz) of the Shoutern Moroccan basin. 


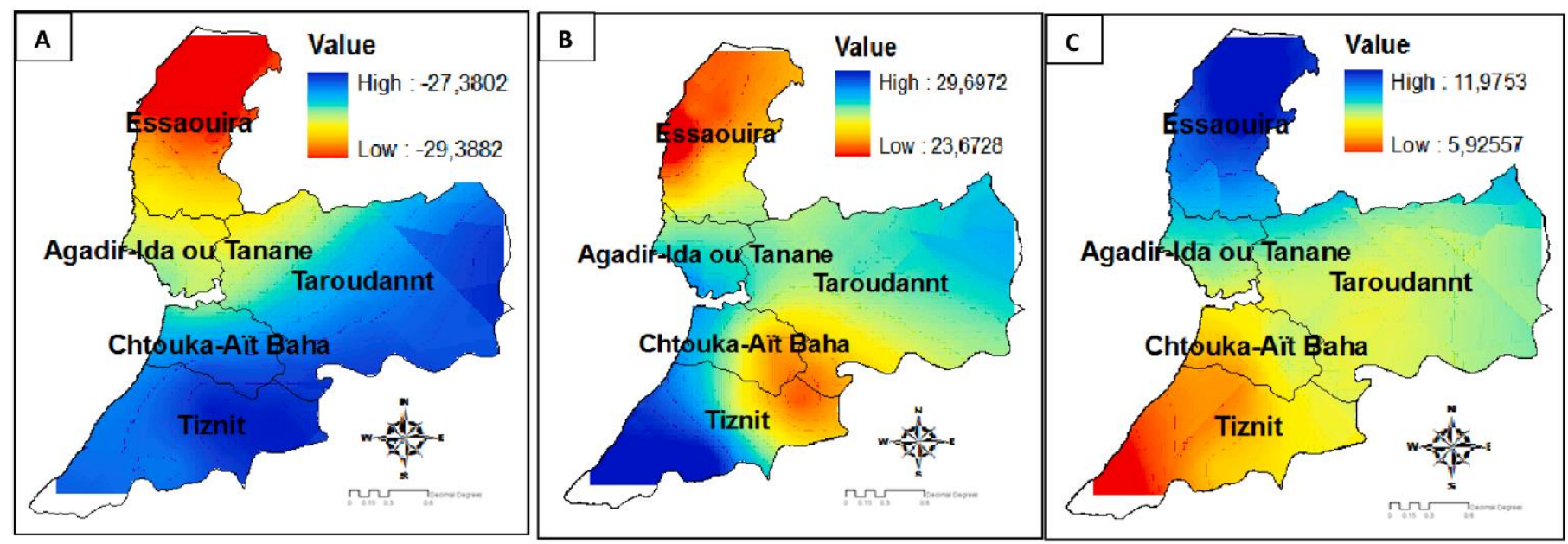

Fig. 4. A, B and C: Argan Oils Isoscapes of (A) $\delta^{13} C$, (B) $\delta^{18} \mathrm{O}$ and (C) Aridity index values In Morocco interpolated from authentic Argan seed obtained from different areas (Essaouira, Agadir Ida ou tanane, Chtouka-Ait baha, Taroudant and Tiznit).

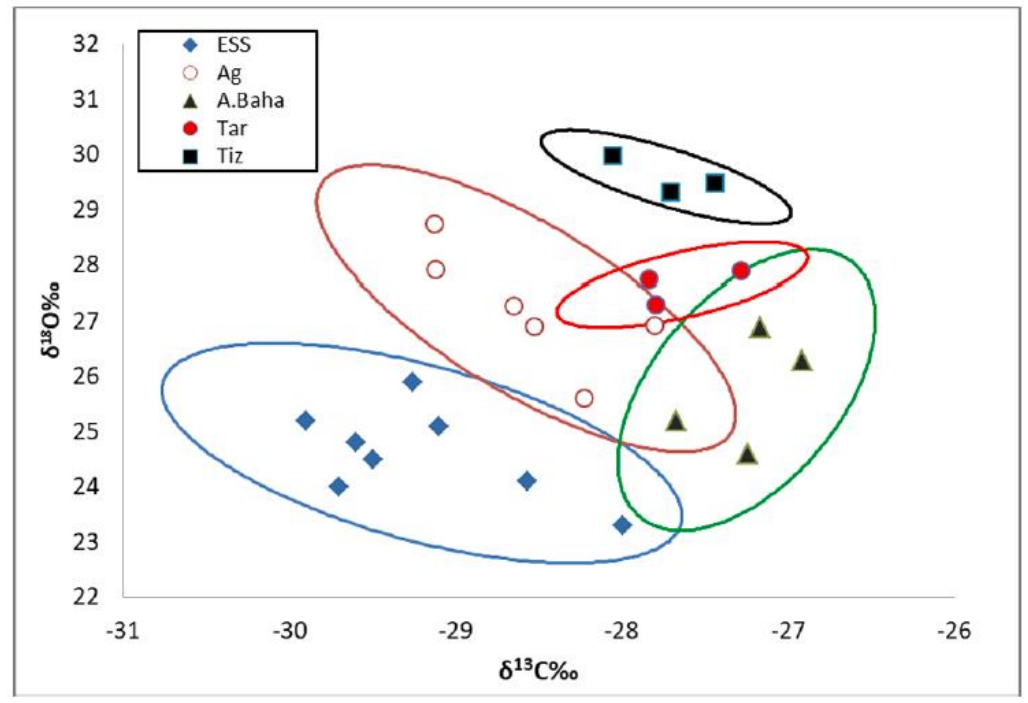

Fig. 5. Relation $\delta^{18} \mathrm{O}$ values versus $\delta^{13} \mathrm{C}$ values of all examined samples: Essaouira(Ess), Agadir Idaou tanan(Ag), Ait bah(A.Baha), Taroudant (Tar) and iznit(Tiz). 


\section{List of Tables}

Table 1 Annual Mean $\delta 180$ of Rain, Isotopic Composition of C, O and N, Topographic and climatic characteristics of the five eco-geographical from southwestern Morocco (protected geographic indication (PGI) of Argan oils regions produced).

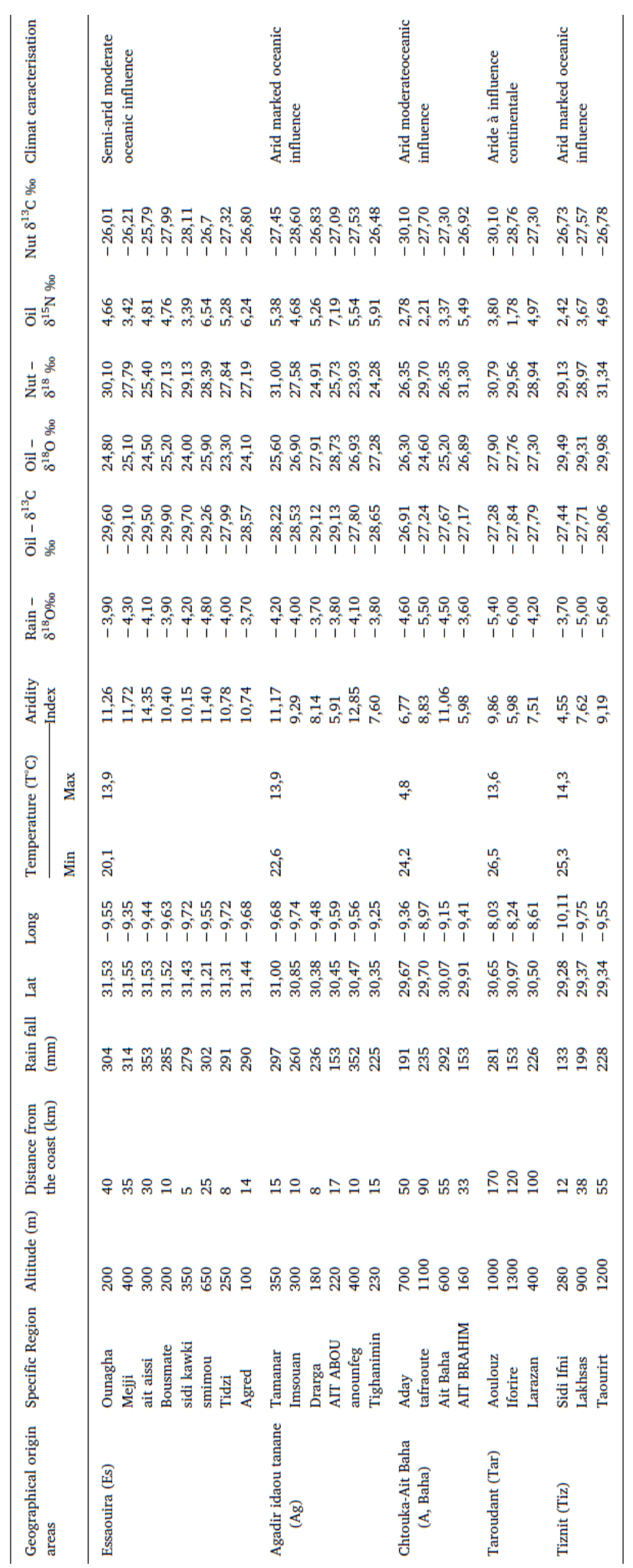


Table 2 Correlations (statistic.oil).

\begin{tabular}{|c|c|c|c|c|c|c|c|c|}
\hline & $\delta^{13} \mathrm{C} \%$ of Oil & $\delta^{18} \mathrm{O} \%$ of Oll & Altitude (m) & Distance from the coast $(\mathrm{Km})$ & Temp $\left({ }^{\circ} \mathrm{C}\right)$ & Rain (mm) & Annual aridity index (AI) & $\delta^{18} \mathrm{O} \%$ of Rain \\
\hline$\delta^{13} \mathrm{C} \%$ of Oil & 1 & $0,93^{*}$ & 0,24 & 0 & $0,73^{*}$ & $-0,53^{*}$ & $0,99^{*}$ & 0,81 * \\
\hline$\delta^{18} \mathrm{O} \%$ of Oil & $0,93^{*}$ & 1 & 0,24 & 0,16 & $0,65^{*}$ & $-0,45$ & $0,92^{*}$ & $0,72^{*}$ \\
\hline Altitude (m) & 0,24 & 0,24 & 1 & $-0,04$ & 0,30 & $-0,34$ & 0,28 & 0,34 \\
\hline Distance from the coast $(\mathrm{km})$ & 0 & $-0,16$ & $-0,04$ & 1 & 0,15 & $-0,17$ & $-0,05$ & $-0,05$ \\
\hline Temp $\left({ }^{\circ} \mathrm{C}\right)$ & $0,73^{*}$ & $0,65^{*}$ & 0,3 & 0,15 & 1 & $-0,73^{*}$ & $0,73^{*}$ & $0,68^{*}$ \\
\hline Rain (mm) & $0,53^{*}$ & $-0,45$ & $-0,34$ & $-0,17$ & $-0,7$ & 1 & $-0,50^{*}$ & $-0,71^{*}$ \\
\hline Aridity index (AI) & $-0,99^{*}$ & $0,92^{*}$ & 0,273 & $-0,05$ & $0,73^{*}$ & $-0,50^{*}$ & 1 & $0,79^{*}$ \\
\hline$\delta^{18} \mathrm{O} \%$ of Rain & $0,81^{*}$ & $0,72^{*}$ & 0,34 & 0,05 & $0,68^{*}$ & $-0,71$ & $0,79^{*}$ & 1 \\
\hline
\end{tabular}

Correlations (oil. statistic).

$\mathrm{N}=23$ (Suppression of the Observ. à VM)

* Significant correlations marked at p $<, 05000$. 